\title{
Commons People: Additive Manufacturing Enabled Collaborative Commons Production (by design)
}

\author{
Dr Paul Smith \\ Institute of Design Innovation, School of Design, Glasgow School of Art \\ p.smith@gsa.ac.uk \\ Dr Marzia Mortati \\ Politecnico di Milano, Department of Design, Italy \\ marzia.mortati@polimi.it
}

\begin{abstract}
"Never doubt that a small group of thoughtful, committed citizens can change the world; indeed, it's the only thing that ever has." - Margaret Mead

In a post industrial age the current model of mass manufacture characterized by integrated organizations and economies of scale, a new production paradigm is emerging. Due to technology advances especially in the field of additive manufacturing (AM) small scale decentralized production is again a possibility. Where once the tools to produce goods were seen as large capital investment beyond the means of most small enterprises, it is now possible for individuals to access tools that are capable of producing consumer goods. This shift had led to the emergence of a social phenomenon that until now was bound to the digital world. Networks of individuals are coming together to collectively design, develop, manufacture and distribute goods through a network under the banner of the open hardware movement. This paper presents a case study of one such network designing and distributing open source prosthetics using a collaborative approach enabled by AM technology. It takes a contemporary definition of commons production as a framework to describe the network and assesses the role AM technology plays within it. Moreover, it discusses the potential role for design (both as a discipline and a profession) within this emerging socio-industrial system.
\end{abstract}

\section{KEYWORDS}

Collaborative Commons, Additive Manufacturing, Open Hardware, Design Innovation

\section{INTRODUCTION}

The recent history manufacturing has a pattern of shrinking and centralising the means of production and controlling the process of new product development from conception to delivery (Rifkin, 2014)(Hugh, 2013), driven by ownership, the market, and monetary value. This model replaced what in Europe was a dispersed model where production was distributed and driven by access, subsistence and intrinsic need. Fast forward to today and the established centralised model still dominates, however there are examples of new ways to produce goods collaboratively (Koren et al, 2013) enabled by new technologies like AM and without the need for a traditional 'firm'. Collaborative production (Siefkes, 2008) enabled by new communication technologies (internet, mobile networks), low cost production tools (laser cutter, 3D printers) and democratic publishing technologies and channels (smart phones, social media, online repositories), has already permeated the fields of information, software and cultural artefact creation. While this type of collaborative content was until recently bound mainly to the digital world producing online content or software, collaborative 
production of physical goods has now started to emerge. Developments in technologies like AM have opened the door for physical artefacts to follow the model set by software, culture and information.

A key element of a collaborative hardware production model is the micro enterprise, individuals and small groups with the capability to produce at small scales. Micro enterprises are not new and developed in transition from the feudal system of economic and social organisation to the proto industrial era that occurred just before the industrial revolution of the 19 th century. In proto industrial society, the phase of rural industry development prior to centralised industrialisation (Hudson, 2015) (Mendels, 1972), small manufacturers producing low volume were distributed (traditionally rurally) and scaled laterally by adding additional small producer 'nodes' to the network. Collaborative production shows signs of similarity to the micro enterprises of proto industry and also some of the values and virtues of a commons approach to organisation that pre dated the proto industry and was characteristic of agricultural feudal society.

The collaborative approach to product development, combining distributed networks and sharing, offers an alternative way of designing, producing and accessing goods. This new 'commons' system for hardware production enabled by AM technologies can revolutionise socioeconomic systems and offer emerging new roles for civic creativity. This paper uses a

case study of the e-NABLE open source prosthesis project to illustrate the network design and function of a modern collaborative production model. It explores the role AM is playing in this production model (AM impact) and what the implications are for commons based production. Further, it explores the contributions of the design profession and discipline to this new production paradigm, as opposite to its traditional collaboration with industry for mass manufacturing.

The first section of the paper explores early commons organisation and its evolution to modern times. It highlights the principles of a commons approach and then the role of technology in a post-industrial production world. It goes on to examine the new role for the designer in this contemporary distributed organisation of production. The next section examines a case study example of a contemporary model of production that uses AM to produce open source prosthetics. The final section draws out some reflections on the role of AM in the model presented through the case study. The paper draws some comparisons to a commons production model building on the theoretical definition of modern commons production. Finally it discuses the potential for further collaborative commons production and highlights some areas for further research.

\section{FEUDAL SOCIETIES AND THE COMMONS}

Feudal society was the major form of economic and social organisation in Europe from about $900 \mathrm{AD}$ up to around the 16th century (Brown, 1974). It was made up mainly of subsistence agriculture where lords who had rights to land gave access rights to peasantry to work the land who then in return paid tribute to their land lords in the way of labour or produce (Rifkin, 2014). In a feudal system no one could be said to own land, everyone who worked the land had a certain domain over it depending on the service to the land they performed (Schlatter, 1973). Working the land effectively enough to survive and pay tribute was a struggle for many individual families and so to maintain themselves feudal farmers combined their resources and efforts into a 'commons' arrangement. A commons is a model based on 
collaborative interest and a desire to connect and share. Many feudal peasant class farmed land collectively by aggregating plots into open fields and shared pasture, maximising resources. Far from being a casual arrangement the commons approach set up governance structures that elected councils to set protocols for use and economic activity. These cooperative governance models ensured that common resources were managed sustainably, produce fairly distributed, protocols set and importantly any punishments decided and enforced. The commons could be characterised by its democratic non-hierarchical governance, collective effort and shared resources, a collective driven by need, social stability and sustainability.

\section{MODERN INDUSTRIAL PRODUCTION: CENTRALISATION}

During this time, production of goods proliferated as labour began to shift from agriculture to manufacture (Crafts, 1989). This was first condensed to micro production (individuals and small factories) and eventually centralised and integrated into mass production. One of the key elements to this radical change in social and economic organisation was technical development of industry (Temin, 1997) and the ownership of tools. Once the private property of individuals and small firms, new tools were now under the ownership of larger firms and the users of tools were transformed to a wage labour force (Rifkin, 2014). Over time production firms sought greater efficiencies and brought more of the production chain 'in house' into vertically integrated firms that could exploit economies of scale to their advantage. What had been a dispersed model of distributed small production had become a centralised model of control and efficiency. The move brought with it greater economic prosperity and abundance of goods at an ever-cheaper cost to consumers and producers.

\subsection{Which economies shape our times?}

The evolution briefly described requires also a short exploration of the current economic system, to frame mass manufacture and the possible return to a commons approach.

Western economies are currently operating in a post-industrial order that bares several dimensions, and has specific characteristics, coming from the evolution that economical functions have undergone during the years. A brief overview of this history is proposed by (Friedman, 2012) who begins with the basic classification proposed by (Clark, 1940) between a primary, secondary, and tertiary sector: the first one is concerned with extracting wealth from nature and includes agriculture, farming, fishing, and so on; the second is key to transforming materials extracted through human labour, and encompasses manufacturing, construction, and production of power; the third one provides other types of services useful to negotiate between human activities and tangible/intangible kinds of goods, including commerce, transport, public administration, personal and professional services. In 1973, "The Coming of Post Industrial Society" written by (Bell, 1973) outlines a new type of post-war society, described as information-led and service-oriented. This is a more complex economic structure that shifts from the centrality of manufacturing and hard fabrication typical of the industrial era, to the importance of services and information technologies central in the postindustrial one. Further, it redefines the strategic assets of economy: from raw material in the pre-industrial society, to financial capital in the industrial one, and human capital in the postindustrial society. Here economic activities become far more variegated than three sectors, adding a quaternary sector with trade, finance, and real estate, and a quinary sector encompassing health, education, research, government, and entertainment. Recently, this post-industrial society is being disrupted by new phenomena, such as the sustainable challenge, the diffusion of information and communication technologies as well as new 
digital social networks, and the introduction of new manufacturing technologies that are quickly reforming material and social culture. For example, interconnectedness has become one of the prominent features of daily life in the form of physical links, flows of goods, money, ideas, and people. Geoff Mulgan (1997) articulates that "this connectedness renders redundant many of the dominant concepts of political, social and economic thought that assumed a world of sovereign and separate entities: nation states, companies and individual citizens. The key intellectual methods needed to understand the contemporary world, by contrast, focus on the character of systems, connections and feedback loops, and on subjects of action who are not seen as complete and bounded" (Mulgan, 1997). Consequently, socioeconomical challenges should now be enquired in systemic ways and through the lens of new strategic assets increasingly linked to human capabilities and social values. The model of the commons described throughout this paper is one example of the emerging ways to regenerate past social value while advancing economy and society in alternative ways.

\subsection{Which resources are important today?}

Closely connected to the shifting economical framework is a discussion around resources, their meaning and importance. Friedman (2012) argues that these have shifted from natural powers, like wind, and water in the pre-industrial era, to manufactured energy, like steam, electricity, and oil in industrial times, while the post-industrial era is centred on knowledge, algorithms, and human interaction. Accordingly, the importance of technology has moved from craft, to machine, to intellect: the centrality of the artisan in the pre-industrial time, shifted to industrial engineers first, and highly skilled workers afterwards with the result of making physical labour increasingly less important. However, what many define a Third Industrial Revolution is proposing unprecedented mixes of resources and labour. Rifkin (2011) talks of an era marked by collaborative behaviour, social networks, boutique professionals, and technical workforces where business practices will be distributed and power will be "lateral" and network-like. Friedman (2012) calls this a sixth economy that uses the power of new materials and technologies to shape biology, molecules, and atoms. In his thoughts, the renovation of the manufacturing base in parallel with the intellectual one is the only way for nations to thrive again, and move away from a stagnating situation. Economic sectors need to cover a full spectrum of activities, which means giving new meaning also to pre-industrial assets like manufacturing. In the same spirit, Micelli (2011) argues for a renewed type of craft future that gives value to a different kind of manual labour encompassing the power of algorithms and additive manufacturing.

Although this represents a great opportunity to reform the economy, it doesn't mean that the old dominant ideas will cease to exist. Rather, less restrictive approaches will pull up alongside the old logic of mechanical causality, which was perfect for industrialization. This means that organisational/productive models will vary according to the level of centralisation of power, and to the level of specialist knowledge in the organisation/network. This describes two polarities:

- $\quad$ More or less Power: The higher or lower concentration of power in the hands of few, which describes the difference between a top-down and a bottom-up innovation approach

- $\quad$ More or less Knowledge: The higher or lower concentration of specialist knowledge in the context where the innovation happens, which describes the difference between an incremental innovation (changes within the existing range of knowledge) and a radical innovation (changes outside the given range of knowledge).

Crossing these axis, four strategies for change emerge that can be described (Mortati, 2013) (Mortati, 2015): 
- community-driven strategies where a group of leaders or experts gets organized to drive a wider network of interested parties and guide them through incremental innovations;

- control strategies which describe situations where knowledge is concentrated in the hands of few experts, who are capable to manipulate it for application. The majority of novelties produced in this case are incremental, as they stem from the same R\&D fountain and principles to become product lines and other types of commodities;

- emergent strategies that are comparable to the traditional diffusion of new technologies, when the power to do something is in the hands of few experts, both because of competencies and resources. In this case innovation can take longer to happen, as knowledge needs time to evolve into learning and to find the right application;

- distributed/collaborative strategies describing disruptive events where resources are balanced between a broader range of actors that experiment together to understand a new phenomenon.

These strategies underpin bottom-up changes lead by culture and behaviour, and largely rooted in the society. This is the case of 3D printers that, although still requiring exploration and development, are capturing the curiosity of the public and offering visions for the renovation of productive systems.

This very quick exploration of strategies for change is especially relevant to underline that economy and innovation are no longer linear and proprietary. Lines of production and consumption, lines of distribution and ideation do no longer follow a precise order. In this shift, design and creativity can play a crucial role to facilitate the advancement of the current distributed/collaborative strategy for change represented by the commons.

\subsection{Which role for design?}

As a function of humans, design is shaped by and interested in social and civic behaviours, from political issues to economical development, from the renovation of the public sphere to the meaning of progress, trust and optimism. Recently, this practice has been stretched further between the necessity to prove its value through economical figures and the wish to bear a greater social responsibility, as it represents neither a sociological practice nor an economical one. On the one side it is linked to imagination and to the definition of a "better world" to enhance people's life, on the other it is strictly connected to industrialization, mass production, and consumerism, because of influences coming from diverse intellectual movements, from the Arts and Crafts to the Ulm School of Design.

In the industrial society, this practice played a niche role, because strictly connected to giving an aesthetic/functional shape to products and connecting this to the brand identity of a firm. In the post-industrial society, design has found increased space as a form of economic activity and an aid to management, not only thanks to the centrality of services that has made its capabilities appealing to companies, but also with a presence in diverse niches of the economy. For example, design is recognized for peculiar links with innovation, and in particular for a punctual and technical contribution to the innovation process in firms, either by innovation in meanings or in aesthetics and product definition (Mortati, 2015) (Utterback et al, 2007). In the new-networked order, designers are scaling up their practice to cover a role that sits further from the logics of function and aesthetic value, and to look more in-depth at the meaning of citizenship and its function in and for society through envisioning relevant new ways to produce goods, services, and even policy.

\section{THE RE-RISE OF THE COMMONS}


The re-emergence of a commons approach - albeit in an evolved form - is the first new economic paradigm to hit the western world since capitalism and socialism in the early 19th century. The new form of commons shares many of the values and virtues of the pre industrial and industrial commons institutions. The new post industrial collaborative commons is concerned with collaboration to connect and share resource to produce goods, enabled by accessible technology like AM, in a way that could rival centralised industrial economies. Underlying the whole 'collaborative commons' approach is the fundamental principle that a contemporary commons holds the freedom to share as virtuous over ownership and the freedom to exclude that comes with it (Benkler, 2006). It is this characteristic that above all links commons style of organisation to the current 'open' movements that have emerged in the last two decades. Those of open software and more recently open hardware. Moreover, after the centrality of intangible type of goods that were valued during the post-industrial economic order (services, digital technologies and tools), a new ethos of material goods is being built that derives directly from the digital world. This is extremely interesting and timely to be studied, as it is updating the old logics of resource production, and - with it - the dominant socio-economical system.

\subsection{From Open Source Software to Hardware}

A Collaborative commons is potentially a powerful tool that could change the way we organise our lives, create and consume goods and democratise the global economy (Open Source Hardware Wiki, 2015). The first major instance of collaborative working through a commons in modern post-industrial times is the open source software movement. Much has been written about open source software and it is not the intention of this paper to re-write its history here but there are elements of the movement that are useful to discuss (Open Source Software, 2015) (Bretthauer, 2001) (Madey et al, 2002) (Oreilly, 1999).

The movement began in earnest in 1998 and has continued to collaboratively develop product ever since. To define software as open source it is not enough to simply release the source code, source must be free to redistribute without restriction, it must permit modifications and derivatives and allow derivatives to be redistributed under the same terms (Oreilly, 1999). The collaborative commons production of software was successful in part because like many successful open collaborative methods inputs and outputs are shared freely (Benkler, 2006). The next step in the open production movement was to bring the digital back into the tangible with open hardware (Rubow, 2015) (Benkler \& Nissenbaum, 2012). Open hardware differs from open software in that the object being developed has to be produced physically with associated costs and constraints. There are issues of protocol and real world constraints, software and hardware exchange can be problematic but large networks can negate this by offering versions for different needs and available resources (Open Source Hardware Wiki, 2015). The open hardware movement allows a lateral network of developers to collaborate on the design and manufacture of real world goods through a collaborative commons approach enabled by accessible manufacturing technology like AM.

\subsection{Collaborative Commons principles}

We are aligning collaborative production networks with a commons approach and so it necessary to explore the key principles of what we consider a commons. The majors tenets of collaborative commons production are: decentralisation - no management hierarchy is dictating; modularity - there are many levels of opportunity to contribute; distribution technology is distributed and accessible (economically and cognitively); creativity - design 
and production involve civic creativity and effort; authorship - although the starting point is usually an original design, this is left to the community for adaptation and improvement; social capital - this is valued as opposed to pecuniary. It also needs quality control and a mechanism to bring together contributions cost effectively, the cost of adding another contribution must stay as close to zero as possible. Commons production brings networks of networks together, each member of a project bring resources to work on the project and so one addition brings their experience, skill, network, and resource, where traditional firm based production limits resources per project. Liberty, autonomy and independence are all offered by commons production, the freedom to opt in or out under no duress from a ruling hand (Benkler \& Nissenbaum, 2012). Table 1 below summarises the combined principles of a commons approach from its origins in agriculture to the more contemporary definition based on recent innovations in production networks. There are self-regarding reasons to get involved in collaborative production such as community and learning, and there are otherregarding reasons, like contributing to others well being, and giving something. Essentially these are the motivations and protocols that govern commons based production, and that are outlining the rise of more resilient and convivial model of production, distribution and consumption. Resilience is the capacity of a system to adapt flexibly to change without being destroyed (Homer-Dixon, 2006). It is the capacity to evolve and survive disruptive events, because each node (people, firm, community) is self-sufficient. Resilience is thus a key quality for future growth together with conviviality. The last is, in Ivan Illich's idea (Illich, 1975) the essential ingredient in connectedness and aims at creating a social life together. According to Illich, a convivial society is based on invention, and promotes people as cocreators of social processes. This idea is central to the reimagining of new socio-industrial systems.

\begin{tabular}{|l|l|}
\hline PRINCIPLE & AIM \\
\hline Collaborative interest & A desire to connect and share \\
\hline Decentralisation & No management hierarchy is dictating \\
\hline Modularity & Many levels of opportunity to contribute \\
\hline Distribution & Technology is distributed and accessible \\
\hline Creativity & Design and production involve civic creativity and effort \\
\hline Authorship & Starting point is usually an original design \\
\hline Social capital & This is valued as opposed to pecuniary \\
\hline Networks of networks & Each member of a project bring resources, resilience \\
\hline Governance structures & Elected councils to set protocols for use and economic activity \\
\hline Sustainability & Common resources are managed sustainably \\
\hline Freedom to share & Virtuous over ownership and the freedom to exclude \\
\hline
\end{tabular}

The next section reflects on these ideas through practice using a case study of a contemporary distributed design and production model. We aim to map and understand its structure and the role of AM in enabling the model. We go on to compare principles of this approach with the theoretical principles outlined above.

\section{CASE STUDY}

This case study used examples of prosthetic designs found through a project website, various online sources of news and user accounts of using the network as source data. Moreover, taking part in community forums and online meetings organised by the e-NABLE project was 
also crucial to gathering more data on the design process. Process analysis (Hall, 2006) was used to map out the variable units in the e-NABLE project looking at the people, the tasks and technologies used in their production process. The collaborative commons principles were used as a framework to assess the correlation between the collaborative commons approach to production and the e-NABLE process. The scope of the case study is to establish an initial map of the network's process to producing prosthetic devices, compare it to a collaborative commons approach and use it to assess the impact of AM technology on the variables in the process.

\subsection{The Network Structure}

The e-NABLE project (www.enablingthefuture.org) was founded in 2013 with the mission to support the growing global community of volunteers who create open source devices and provide easily accessible information for children and adults with upper limb differences who are in need of a 3D printed helping hand. The project has (at the time of writing) 6768 members worldwide, organized into a global network with about $2 / 3$ based in the USA. Between 2013 and 2016 it has reportedly delivered an estimated 1500 open source prosthetic hands manufactured using AM technology to people around the world. The network is made up of volunteers who elect to use their skills to develop the low cost prosthetic designs and release them for free through the network. As well as designing the devices the volunteers also produce devices and most often they are produced locally near to the recipient who will use it. Many of the members of the network are owners of there own 3D printers that are predominately of the fused deposition modelling technology (FDM) variety. The group produce, maintain and govern the common ground that holds all the network data. To use one of the current devices available through the network individuals must have a functional wrist or elbow to make most current and recommended e-NABLE devices operate properly but volunteers will work with users to develop custom devices as well as the standard versions. 'Clients' can approach the network with a request for a device and the network will match them with a local volunteer who can provide the device. Material costs are approximately $\$ 35$ (as of writing) for an e-NABLE 'raptor' hand, this compares with $\$ 6000$ for a basic prosthetic hand. Currently there are 10 recommended designs available through the e-NABLE website (Website, 2015).

\subsection{Device development and production}

The network began with an original prosthetic device design. This design was released as open hardware so that it could be downloaded, developed and produced without charge. The design files along with the data to support the manufacture and assembly of the device were made publically available through a third party platform. As the network developed other variables were added to the system, including more volunteers adding to the lateral scale of the network and enhancing the system capability. The expansion of the network brings with it the addition of individual resources (design technology, production technology, skills, knowledge, distribution capability) and increases the resilience of the network. There are protocols that maintain the ethos of the network and quality of the data within it. These protocols guard against a closed system and ensure that the designs of the devices are open for the community to develop. The development process is spread among all members and not a select few. Developments are quality checked by a core team, there are governance standards that maintain a minimum standard and maintain that only approved developments are officially fed back into the network. While there is no enforced hierarchy in the network there is a commonly accepted level of quality that drives the governance of the network. Having a range and variety in the level of skills seems necessary for the collaborative 
commons approach so that learning can take place between members. There are cases where new devices based on designs taken from the network will appear on open source platforms but the network does not sanction these designs.

Figure 1 shows how the distributed approach to this project works. There is a central repository, the website and affiliated data storage, that facilitates the network. Individuals, virtual clusters or groups of volunteers take data from the network to develop new devices with approved devices being put back into the shared resource in a loop. Anyone who needs a prosthetic device approaches the volunteers through the project website and through this connection gets access to the most local individual who can provide the device. At the heart of the material structure of this model is the AM unit. It is at the point of connecting a client with volunteers that the devices are made physical using AM technology. At the same time, the heart of the network is represented by the designs that are shared, adaptable, and open.

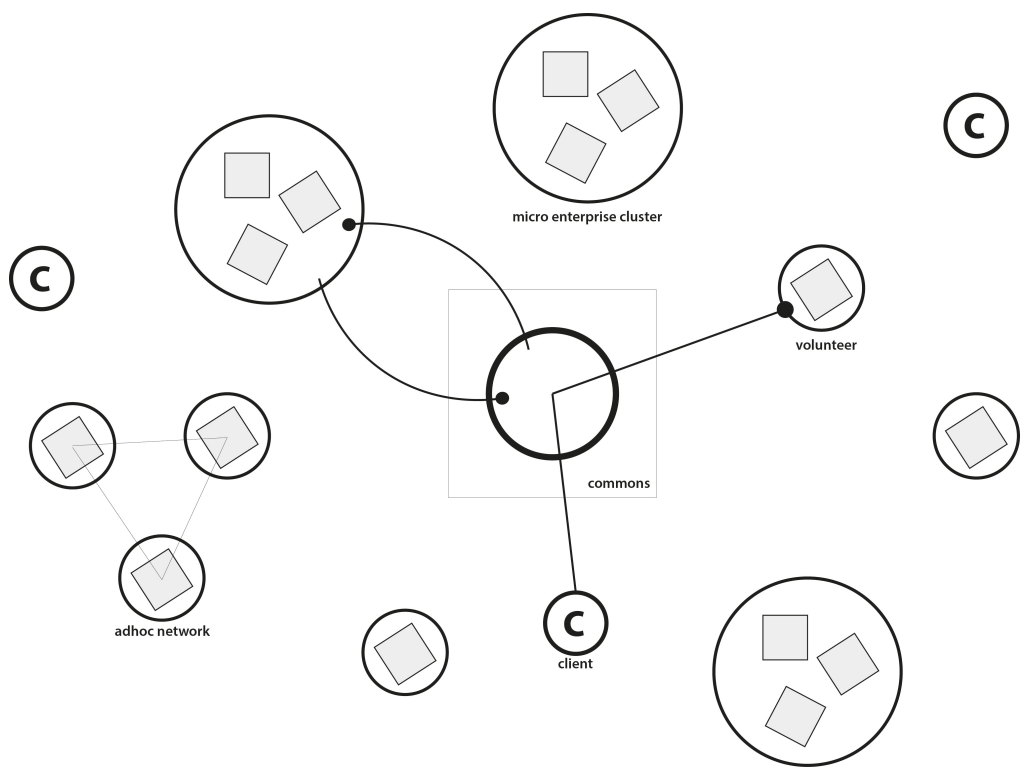

Figure 1: The network diagram of e-NABLE

\subsection{Network principles}

The model invoked by e-NABLE shares many of the characteristics of a collaborative commons. It has various levels of opportunity for people to contribute and it is lateral in scale and decentralised. The latter two points are made possible in part by the capabilities of AM technology. Being able to produce in low volumes cost effectively and with low cognitive barriers means that manufacturing can be dispersed, and the cost of adding another node to the network is also low, thus scaling laterally is possible. This ability also means that volunteers can come in and out of the network easily so they can elect themselves for contributions at the level they feel they can pitch. This was possible because of the proliferation of low cost AM systems that allow the prosthetic devices to be produced as individual units cost effectively and customised at the point of delivery in a global network. The network operates with a free access policy that allows anyone with the means to produce a device to contribute. By being open to input as well as output the network has the opportunity to draw on a broad creative as well as technical resource akin to the open source software movement. There are no obvious pecuniary benefits to being part of the network but there may well be associated benefits that link to a financial incentive, this may be an 
interesting area for further investigation. In this model we see elements of what Mulgan (1997) refers to as connectedness, networks, and actors in a network who are not bounded either by nation of firm. Rifkin (2011) described a new era of collaborative behaviour and social networks, both of which are prescient in the example. It has what Benkler \& Nissenbaum (2012) identify as the ability to opt in or out under no duress form a ruling hand and a certain degree of autonomy. These factors pertain to what Homer-Dixon (2006) recognises as a resilient system, in that it is flexible and consists of independent nodes. A question posed by this research was the similarity of the case study to a commons approach to production. In this section we have described some of these similarities. If we now take table 1 that summarises the contemporary commons approach developed in this paper we can start to align instances from the example to the principle aims to make a clear distinction to the similarities.

\begin{tabular}{|l|l|}
\hline PRINCIPLE & AIM \\
\hline $\begin{array}{l}\text { Collaborative } \\
\text { interest }\end{array}$ & $\begin{array}{l}\text { There is no significant monetary benefit to take part, devices are } \\
\text { designed and developed collectively i.e. through online events }\end{array}$ \\
\hline Decentralisation & $\begin{array}{l}\text { While there are administrators of the project site and mechanisms to } \\
\text { control quality there are no discernable 'managers' that control and } \\
\text { distribute 'work'. }\end{array}$ \\
\hline Modularity & $\begin{array}{l}\text { Volunteers can enter as designers, producers, make comments, } \\
\text { maintain web content, etc. There are many roles. }\end{array}$ \\
\hline Distribution & Technology is distributed and accessible \\
\hline Creativity & $\begin{array}{l}\text { The devices are developed throughout the network, the question of } \\
\text { civic versus professional is blurred in this sense but there is no } \\
\text { restriction preventing citizens creative input }\end{array}$ \\
\hline Authorship & $\begin{array}{l}\text { The project is based on an original design and all new developments } \\
\text { are open to modification, derivation and adaptation. }\end{array}$ \\
\hline Social capital & $\begin{array}{l}\text { The network does not have central significant financial capital, it relies } \\
\text { on social capital and accumulated individual inputs }\end{array}$ \\
\hline $\begin{array}{l}\text { Networks of } \\
\text { networks }\end{array}$ & $\begin{array}{l}\text { Nodes in the network bring skill sand equipment to the overall } \\
\text { network }\end{array}$ \\
\hline $\begin{array}{l}\text { Governance } \\
\text { structures }\end{array}$ & $\begin{array}{l}\text { There are structures that maintain quality control and a set of core } \\
\text { values are enforced by the community to guard against exploitation }\end{array}$ \\
\hline Sustainability & $\begin{array}{l}\text { Information and data are the common ground in the network, } \\
\text { equipment remains largely owned by individuals or groups but is used } \\
\text { to the benefit of the network, } \\
\text { The basis for the whole project is that data is shared }\end{array}$ \\
\hline $\begin{array}{l}\text { Freedom to share } \\
\text { \& derive }\end{array}$ & $\begin{array}{l}\text { Device designs are released without restrictions on derivation or } \\
\text { adaptation }\end{array}$ \\
\hline
\end{tabular}

Table 2: evidence of a commons approach

The table highlights that for the main the example presented in this paper shares the characteristics of a contemporary commons approach to production. The question of sustainability in terms of sustainably managing resources is an interesting point. The network produces at source and so energy use is also at source that distributes the consumption. In terms of resource consumption the network essential lies 'dormant' until needed and so resource in this sense is only consumed when it is needed. It is not clear whether there is a collective approach to sustainable material use and a picture of collective resource use cannot be drawn and this could frame an interesting direction for research. We have added an extra 
principle to the definition presented in table 1, that of freedom to derive and adapt. In a contemporary commons approach what is produced is freely open to further development through appropriation of data and freedom to adapt.

\section{DISCUSSION}

\subsection{New micro firms?}

An interesting open discussion linked to the case and ideas presented concerns the emergence of a new type of firm. This is valuing networks differently and beyond traditional marketing propositions, that is creation of reputation through increase of contacts. Networks are contributing to rethinking the mechanisms of production using new technologies like AM, to imagine new paths to growth beyond turnover, and to give new roles to users along the innovation process by means of ICTs. This is not yet fully in focus, but rather a research topic up for discussion. In the search for the next big paradigm that can drive industry success, the Ericsson industry observatory reports: "Technological revolutions lead to new ways of thinking about techno-economic issues. Such transformations reach beyond the industry in question to society at large, and evolve to become the shared basic principles of the period. In the era of cars and mass production, the shared principles were related to mass markets, economies of scale, standardization, centralization and hierarchies. In contrast, the guiding principles of the information age are decentralized integration, network structures, adaptability, agility, customization, knowledge as capital, clusters and economies of scope" (Ericsson 2013: 3). In this paradigm, consumers/users participate in flexible networks for product development and become part of the design and innovation process. Mediated through ICTs and enabled by distributed and decentralised manufacturing, users can have direct input into new product development, thus transforming the way we make things. In the past, firms were only considered economical objects from which profit had to be gained. Their value was reflected in the concept of the stock price, and their main asset was management - the core activity to satisfy investors' interests. This idea has held true for centuries, however recently projects like e-NABLE are describing alternative network-based business models grounded on positive social impact and personal satisfaction. This field is still uncertain, both in the way it will evolve and in the idea of obtaining more concrete commercial outputs, especially if considering commercial value in the traditional way. To understand what this will be in the future is currently an open question, upon which few models have been put forward to propose new answers, although often remaining anchored to old value creation systems. The theory referred to as Open Innovation (Chesbrough et al, 2006) for example, is an attempt to open up proprietary innovation funnels, which remains though an old innovation paradigm, common in traditional hierarchical and multinational firms. On the contrary, new types of firms should be looking for original and looser mixes of tools and competences, control and flexibility, personal and professional life. This is becoming possible because of desktop manufacturing tools and connective mobile technologies that are enabling an increasing number of people (professionals as well as amateurs) to transform their idea into reality. Examples of self-managed manufacturing plants are popping up around the world relying on outsourcing operations through online services. Examples of this span from digital platforms offering manufacturing services like Ponoko https://www.ponoko.com/, to avanguard experimentations become real products and services like Biocouture (http://www.biocouture.co.uk/), a biocreative design consultancy that helps brands imagine their 'biodesigned future', by creating new materials out of experimentation with microorganisms. This new firms are highly experimental, flexible and distributed in terms of resource management and acquisition. They deploy new productive processes, like 
the one demonstrated by e-NABLE, that from an organisational point of view can be described as collaborative service networks requiring almost no internal specialist physical assets. The core of this new type of micro firms is not necessarily the hardware (although as this paper highlights it does have a key role), for example the productive plant, but rather the ability, motivation, and opportunity, that is the social exchange necessary to connect places, resources, necessities and opportunities (Mortati, 2013). This emergent innovation model affects economy, sociology, and management, talking of new business opportunities and new entrepreneurial profiles (i.e. the digital craftsman - Micelli 2011). The shift is quite important for the firm of the twenty-first century that is increasingly based on the strength of relationships, the value of local resources, small numbers and excellence, all assets that deserve further investigation into their current and future meaning.

\subsection{Framing design in the collaborative commons model}

A second important discussion concerns the centrality of design in the emergent networkbased micro firms. Traditionally, design is linked to manufacturing, industrial goods produced in large scale, consumer taste, function, price, and so on (Flusser, 1999). However, as in the scenario described in the previous paragraphs, design has begun to look beyond consumers' taste and price. Two elements are crucial when seeking to frame this complex landscape: the first one is organizational, and focuses on the way in which companies establish their collaborations and arrange their supply chain. This is relevant because the model presented revises the traditional relationship between designer and firm. Whereas one-to-one elective relationships used to make design a core value for a commercial offer (i.e. in the case of made in Italy - De Fusco, 1985), the current value chain uses digital technologies to multiply links and evolve the traditional designer-entrepreneur-consumer connection into a network of networks, where each stakeholder represents a complex system of interchanges. The second dimension looks at an open design process (Tooze et al, 2014) to stimulate participation. Traditionally, designers have been stand-alone talented individuals. Increasingly, they participate in multi-disciplinary teams of experts and non-experts, made up of people who share ideas and open it to others for improvement. According to Paul Atkinson (Atkinson, 2006) this is a transition from an era of vertical flow to a collaborative and open one, made possible mainly because of the possibility of using technologies that allow designing through code. This allows wider openness for sharing knowledge and experimenting, thus multiplying the possibilities for the democratization of design.

\section{FURTHER WORK}

In terms of the role AM plays in a new production model and the implications for further commons based production, it appears that in a commons production model networked micro enterprises are the core to development. They design, build, develop and provide the product direct to the consumer and critical to the micro unit is accessible manufacturing such as AM. It is the ability to distribute manufacture laterally that allows a network of open hardware to flourish. There are some technical issues surrounding a collaborative commons approach to production through micro enterprise. The first and most salient is that AM has protocols. Generating the files to produce devices and transfer to other units is seamless enough but original design files are not all cross platform compatible. However, this can be negated by large networks with capacity reproduce files in the right format, printers share much of the same protocols but again large networks can produce versions for different technologies, designs can be modified at source and produced either at source or through the network. It seems that the maturity of AM technologies (as well as other digital fabrication) and the 
inevitable affiliated drop in cost could see an abundance of new products developed, shared and manufactured across a collaborative commons of laterally scaled enterprises. It is now possible to produce hardware in an open and collaborative way through a dispersed network using commons approaches with accessible technologies that will inevitably improve with time.

Our case study network currently uses predominantly FDM technology to produce devices. Rationally this is because FDM has been the subject of most development in recent times and is the most accessible option (in terms of monetary and cognitive cost). However, resin and powder based technologies are set to follow a similar pattern and so devices will inevitably improve. There are already a number of prosthetic devices that have been produced with SLS technology and the impact of improved production should be considered.

On a technical and practical level, further research on the commons approach to production could focus on the protocols of file exchanges, as this is one of the issues to a true open source approach. As well as a focus on this element, it would be valuable to begin to develop a framework that could assess suitable products as candidates for this type of production model. A suitable starting point for this would be a detailed analysis of the example devices in this study through a series of workshops that would develop an initial frame. The frame could look at elements like the number of volunteers in the network with the aim of ascertaining if there is a critical mass needed for success. Equally looking at the demographic of volunteers could reveal much about the motivations and conditions for individual participation. Product type might form another part of the frame with the aim of categorising products as candidates for this type of production.

On a theoretical level, issues concerning the study of the new type of micro firm and the different nature of its assets - both organisational and technical - need to be investigated further through multi-disciplinary research paths looking at amplifying emergent and positive new models of production and consumption. In terms of how applicable the model might be in other industrial applications. As Temin (1997) points out, radical change in social and economic organisation was technical development of industry. We have seen mechanisation, automation and now democratisation of tools that could enable another radical change.

\section{REFERENCES}

Atkinson, P., 2006, Do It Yourself: Democracy and Design, Journal of Design History, Vol. 19. No. 1., Journal article

Bell, D., 1973, The Coming of Post-Industrial Society: A Venture in Social Forecasting, New York, Basic Books, Book

Benkler, Y., 2006, The Wealth of Networks, Yale University Press, Book

Benkler, Y. \& Nissenbaum, H., 2006, Commons based peer production and virtue, The Journal of Political Philosophy, Volume 14, Number 4. Journal article

Bretthauer, D., 2001, Open Source Software: A History, UConn Libraries Published Works, Paper 7. Book 
Brown, E. A. R., 1974, The Tyranny of a Construct: Feudalism and Historians of Medieval Europe, The American Historical Review, Vol. 79, No. 4. Journal article

Chesbrough, H. W., Vanhaverbeke, J., West, J., eds, 2006, Open Innovation: Researching A New Paradigm, Oxford, Oxford University Press, Book

Clark, C., 1940, Conditions of Economic Progress, London: Macmillan and Co, Book

Crafts, N., 1989, British Industrialization in an International Context, Journal of Interdisciplinary History. Journal article

De Fusco, R., 1985, Storia del design. Milano: Edizioni Laterza.

Flusser, V., 1999, The shape of things: a philosophy of design. London: Reaktion Books. Book

Friedman, K., 2012, Models of Design: Envisioning a future design education, Visible Language, 46 (1/2). Journal article

Hall, P., 2006, Systematic process analysis: when and how to use it, European Management Review. Journal article

Homer-Dixon, T., 2006, The Upside of Down: Catastrophe, Creativity and the Renewal of Civilization, USA, Island Press, Book

Hudson, P., 1990, Proto-industrialisation, ReFRESH (Recent Findings of Research in Economic \& Social History), http://www.ehs.org.uk/dotAsset/1d40418e-b981-4076-8974b81686a9d042.pdf accessed 9.12.2015. Online article

Hugh, S., J, 2013, Evolving Paradigms of Manufacturing: From Mass Production to Mass Customization and Personalization, Proceedings from the Forty Sixth CIRP Conference on Manufacturing Systems. Conference paper

Illich, I., 1975, Tools for Conviviality, London, Fontana, Book

Koren, Y., et al., 2013, Open-architecture products, CIRP Annals - Manufacturing Technology, Volume 62, Issue 2. Journal article

Madey et al., 2002, Open Source Software Development Phenomenon, Eighth Americas Conference on Information Systems. Conference paper

Mendels, F., F., 1972, Proto-industrialization: The First Phase of the Industrialization Process, The Journal of Economic History, Vol. 32, No. 1. Journal article

Micelli, S., 2011, Futuro Artigiano, Venezia, Marsilio,

Mortati, M., 2015, A Framework for Design Innovation: Present and Future Discussions, Design Issues, volume 31, number 4. Journal article 
Mortati, M., 2013, Systemic aspects of Innovation and Design. The perspective of

Collaborative Networks, PoliMI Springer Briefs,

Mulgan, G., Connexity. 1997, How to live in a connected world, Harvard: Harvard Business, Book

Open Source Hardware Wiki, https://en.wikipedia.org/wiki/Open-source_hardware, accessed 15.11 .15

Open Source Software, https://en.wikipedia.org/wiki/Free_and_open-

source_software\#cite_note-FOOTNOTEWilliam2002-11, accessed 18.11.2015

Oreilly, T., 1999, Lessons from open-source software development, Communications of the $A C M$, Volume 42 Issue 4, April. Journal article

Powell, A., 2012, Democratizing Production through Open Source Knowledge: From Open Software to Open Hardware. Book

Rifkin, J., 2011, The Third Industrial Revolution: how lateral power is transforming energy, the economy, and the world, New York: Macmillan, Book

Rifkin, J., 2014, Zero Marginal Cost Society, Book, Palgrave Macmillan. Book

Rubow, E., Open Source Hardware,

https://cseweb.ucsd.edu/classes/fa08/cse237a/topicresearch/erubow_tr_report.pdf, accessed 17.11.2015

Schlatter, R., 1973, Private Property: the history of an idea, Book, New York, Russell and Russell. Book

Siefkes, C., 2008, Generalizing Peer Production into the Physical World, EDITION C.

SIEFKES. Book

Temin, P., 1997, Two Views of the British Industrial Revolution, The Journal of Economic History, Vol. 57. Journal article

Tooze et al Tooze, J., Baurley, S., Phillips, R., Smith, P., Foote, E., Silve, S., 2014, Open Design: Contributions, Solutions, Processes and Projects, The Design Journal, Volume 17, Issue 4. Journal article

Utterback, J., Vedin, B., Alvarez, E., Ekman, S., Sanderson, S., Tether, B. et al., 2007, Design-Inspired Innovation, London, World Scientific Publishing, Book

Website, http://enablingthefuture.org, accessed 16.11.2015

Wohlers Report 2015 
